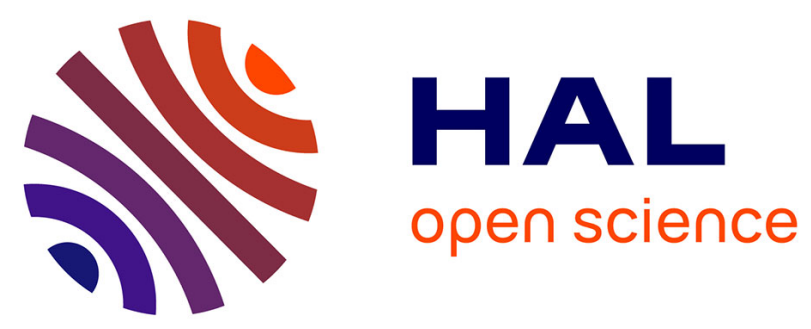

\title{
New Definition of Critical Energy for SiC MOSFET Robustness under Short- Circuit Operations: the Repetitive Critical Energy
}

C. Chen, Tien-Anh A Nguyen, D Labrousse, S Lefebvre, Cyril Buttay, Hervé Morel

\section{To cite this version:}

C. Chen, Tien-Anh A Nguyen, D Labrousse, S Lefebvre, Cyril Buttay, et al.. New Definition of Critical Energy for SiC MOSFET Robustness under Short- Circuit Operations: the Repetitive Critical Energy. Microelectronics Reliability, 2020, 114, pp.113839. 10.1016/j.microrel.2020.113839 . hal-02968998

\section{HAL Id: hal-02968998 https://hal.science/hal-02968998}

Submitted on 16 Oct 2020

HAL is a multi-disciplinary open access archive for the deposit and dissemination of scientific research documents, whether they are published or not. The documents may come from teaching and research institutions in France or abroad, or from public or private research centers.
L'archive ouverte pluridisciplinaire HAL, est destinée au dépôt et à la diffusion de documents scientifiques de niveau recherche, publiés ou non, émanant des établissements d'enseignement et de recherche français ou étrangers, des laboratoires publics ou privés. 


\title{
New Definition of Critical Energy for SiC MOSFET Robustness under Short- Circuit Operations: the Repetitive Critical Energy
}

\author{
C. Chen, T.A. Nguyen, D. Labrousse, S. Lefebvre, C. Buttay, H. Morel
}

\begin{abstract}
Previous research showed that Si devices could sustain a large number of Short Circuit (SC) events, as long as the energy dissipated during SC remains slightly below a given threshold (the so-called critical energy). In this paper, we show that this is not necessarily true for SiC MOSFETs, which can only withstand a few such SC events. This low robustness to repetitive short-circuit events is related to the gate degradation due to the cumulative carrier injection and leakage currents in the oxide. To ensure safe operation over a large number of SC events, we introduce a new parameter: the "repetitive critical energy", which corresponds to a SC energy low enough to avoid excessive temperature increase so as to limit the transient gate leakage current during SC events. Below this repetitive SC energy value, the SiC device is able to sustain a large number (more than 1000) of SC events.
\end{abstract}

\section{Introduction}

As a semiconductor material, $\mathrm{SiC}$ has much better physical characteristics than silicon (wider bandgap, higher avalanche critical electrical field, higher thermal conductivity) [1]. Nowadays, power MOSFETs are the most common type of SiC transistors available on the market. Compared to Si devices of the same voltage ratings, $\mathrm{SiC}$ MOSFETs offer a lower on-state voltage drop, higher switching speeds and a lower leakage current in the off state. However, it is crucial to characterize the robustness and reliability of power SiC MOSFETs before they can be implemented on a large scale in electrical energy conversion systems. Over the last few years, various studies have investigated the robustness of SiC MOSFETs in the case of short-circuits (SC) and avalanche breakdown.

Thanks to their lower specific resistance [1], SiC dies tend to be smaller than those of comparable Si devices. This results in a higher current density which, together with the high electrical field encountered during SC events, produces a higher density of power dissipation. It should also be mentioned that the active layer of SiC MOSFETs is much thinner than that of silicon devices of the same blocking voltage. These features cause a faster temperature rise of the $\mathrm{SiC}$ dies, and a shorter time to failure, especially at high drain to source voltages [2-4] or when the device is turned on with a high gate to source voltage [5]. These different papers have shown that SiC MOSFETs are much weaker than $\mathrm{Si}$ devices with similar current and voltage ratings in SC stress.

For low gate to source voltage $(10 \mathrm{~V})$ and consequently low saturation current during SC events, the failure mechanisms are characterized by the trapping of positive charges into the gate oxide above the channel region or at the interface. This results in the decrease of the threshold voltage and the increase of the drain leakage current after the SiC MOSFETs have been submitted to repetitive SC events [6].

Under higher gate to source voltages, two different failure modes have been pointed out [7]. The first one is a failure during the SC (or a delayed failure mode) which is due to thermal runaway. In these conditions, experiments show a change in the current slope at the end of the SC pulse for SC durations close to the failure and a current tail after a safe opening of the SC current [8]. The second failure mode involves the degradation of the gate and can result in a SC between gate and source electrodes $[9,10]$. Several studies also report the apparition of a gate leakage current during SC events for discrete components and modules $[3,9,10,11,12]$. The gate leakage current, which depends strongly on the gate to source and drain to source voltages [11], has been related to the Fowler-Nordheim current which is affected by the temperature [13,14]. A recent paper points out that Schottky emission is most likely to be the mechanism explaining the large gate current observed in $\mathrm{SiC}$ MOSFET during SC operation [15]. It has also been shown that the repetition of SC events can quickly lead to a gradual increase of the gate leakage current during SC and irreversible degradation [10]. The failure mechanisms have been investigated by several authors, although the results are still controversial. For both failure modes, electro-thermal simulation results show that failure appears at $650{ }^{\circ} \mathrm{C} \pm 100^{\circ} \mathrm{C}$, i.e. close to the melting temperature of the topside metallization of the dies (aluminum) [16], and much lower than the thermal runaway temperature $>1200{ }^{\circ} \mathrm{C}$ for $1200 \mathrm{~V} 4 \mathrm{H}-\mathrm{SiC}$ [17]. Another paper shows that the temperature at failure in the crystal is between 1600 and $2000 \mathrm{~K}$, depending of the failure mode (fail to open or fail to short respectively) [18]. Furthermore, even if the gate oxide has been identified to be the weakest part of $\mathrm{SiC}$ MOSFETs, micro-structural failure analyses made on commercial devices did not show cracks in the gate oxide but mainly in the field oxide, which nevertheless results in a path between the polysilicon gate and the source terminal $[19,20]$.

The SC Safe Operating Area (SCSOA) of silicon IGBTs was defined many years ago [21-23], and these components are typically able to withstand the repetition of a high number of SC cycles (typically 1000s) with a duration of less than $10 \mu \mathrm{s}$ at a voltage equal to half of $V_{B R}$. Previous studies have highlighted the existence of a critical energy $\left(E_{C}\right)$ which separates two distinct stable failure modes for Si IGBTs. For an energy level below the critical value, devices can withstand a large number of SC cycles before failure. As soon as the SC energy exceeds even so slightly the critical energy, the devices fail at the first SC test in a "delayed failure mode" [23]. A tail current takes place after the turn-off process of the device and leads to a destructive thermal runaway phenomenon after several tens or hundreds of microseconds. This critical energy value is related to the temperature inside the device, which rises to a level where collector leakage current becomes excessive.

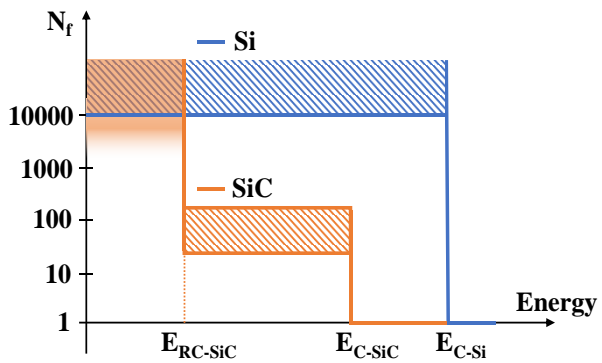

Fig. 1. Repetitive critical energy for evaluating the SC robustness of $\mathrm{SiC}$ MOSFETs ( $E_{R C}$ : repetitive critical energy, $E_{C}$ : critical energy, $N_{f}$ : number of SC events to failure).

In this paper, we investigate the critical energy $\left(E_{C}\right)$ of $\mathrm{SiC}$ MOSFETs manufactured by Wolfspeed. The paper will show that contrarily to Si devices, which can survive many SC events providing their energy is slightly lower than the critical energy, SiC MOSFETs can only withstand a few such SC events. The reason of their fast degradation will be related to the gate oxide 
degradation due to the repetition of carrier injection in the oxide or to the formation of cracks in the field oxide leading to a conductive path between gate and source terminals. In order to define a Safe Operating Area (SOA) that is valid over a large number of SC events, we introduce a new critical energy parameter: the "repetitive critical energy" $\left(E_{R C}\right)$ for $\mathrm{SiC}$ MOSFET (see Fig. 1). It corresponds to a SC energy low enough to avoid excessive temperature increase so as to limit the transient gate leakage current during SC events.

\section{Experimental protocol}

The SC test bench is presented in Fig. 2. 4H-SiC MOSFETs rated at $1.2 \mathrm{kV}-80 \mathrm{~m} \Omega(\mathrm{C} 2 \mathrm{M} 0080120 \mathrm{D}$, Wolfspeed) were selected as the Devices Under Test (DUTs). The SC test bench allows providing SC stress with a maximum DC voltage of 900 $\mathrm{V}$, a maximum SC current of $400 \mathrm{~A}$ and a tunable SC pulse width.

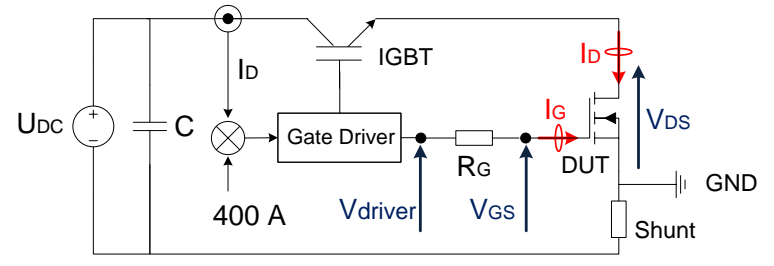

Fig. 2. Short-circuit test bench.

The SC currents are measured using a $10 \mathrm{~m} \Omega$ coaxial shunt (T\&M Research SBNC-2-01) connected in series with the source terminal of the MOSFET, while $V_{D S}$ is measured using a Tektronix P5100A, high-voltage probe $(2.5 \mathrm{kV})$ designed for high frequency (up to $500 \mathrm{MHz}$ ). The gate current $I_{G}$ can be calculated using (1).

$$
I_{G}=\frac{V_{\text {driver }}-V_{G S}}{R_{G}}
$$

where $V_{\text {driver }}$ is the output gate driver voltage, $V_{G S}$ is the gatesource voltage and $R_{G}$ is the gate resistance.

$V_{\text {driver }}$ and $V_{G S}$ are measured using Tektronix P6139B voltage probes rated at $300 \mathrm{~V}$. The DUT is mounted on a temperature-regulated hot plate that sets its case temperature, to observe the influence of the initial junction temperature (from $25^{\circ} \mathrm{C}$ up to $150{ }^{\circ} \mathrm{C}$ ) on the robustness of the DUT.

The energy dissipated $\left(E_{d i s}\right)$ inside the DUT is calculated from the $V_{D S}$ and $I_{D}$ waveforms captured during the SC phase by integrating $V_{D S} \times I_{D}$ over the duration of the SC pulse $t_{S C}$ :

$$
E_{\text {dis }}=\int_{0}^{t_{S C}} V_{D S} \cdot I_{D} d t
$$

The critical energy $\left(E_{C}\right)$ [23], which is an essential metric of robustness for power devices, refers to the minimal amount of dissipated energy that leads to the failure of the tested device after one single SC. With the purpose of estimating this critical energy, the SC duration is gradually increased from a low value (where the device can safely turn-off the SC current) up to the failure point. The maximum energy the device is able to sustain during a safe SC test is recorded as the critical energy. Note that this methodology assumes that the repetition of the SC events has no effect on $E_{C}$, i.e. that there is no wear-out mechanism that would cause a progressive degradation of the DUT. As we will demonstrate, this assumption does not necessarily hold true, which is why at first SC duration is increased with coarse steps, so as to limit the number of SC events.

\section{Critical energy and junction temperature estimations}

A series of SC tests was carried out for the purpose of critical energy evaluation. In a first step, as a trade-off between the accuracy of $E_{C}$ estimation and preventing accelerated aging of the DUT, $\Delta t_{S C}=0.5 \mu \mathrm{s}$ has been chosen as a fixed time increment. The tests were performed at $U_{D C}=600 \mathrm{~V}, T_{C A S E}=25$ ${ }^{\circ} \mathrm{C}$ and $150{ }^{\circ} \mathrm{C}$ and $R_{G}=47 \Omega$.

The results are plotted in Fig. 3.a and Fig. 4.a, where $V_{D S}$ and $V_{G S}$ are presented on the left scale and $V_{G S}$ is multiplied by 20 to match the $V_{D S}$ scale.

At $T_{C A S E}=25{ }^{\circ} \mathrm{C}$, for $t_{S C}=8,8.5$ and $9 \mu \mathrm{s}$, the drain current returns to zero after the DUT has turned off. However, for $t_{S C}=$ $9.5 \mu \mathrm{s}, 4 \mu \mathrm{s}$ after the turn-off, a delayed failure appears, causing a SC between all three terminals of the device (Fig. 3.a). If we consider $t_{S C}=9 \mu \mathrm{s}$ (the highest value resulting in a safe turn-off), the critical energy $E_{C}$ can be estimated to about $726 \mathrm{~mJ}$.

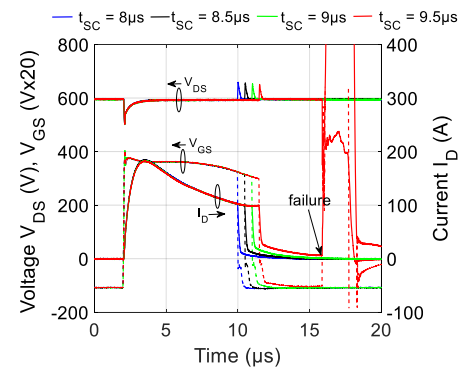

(a) (b)

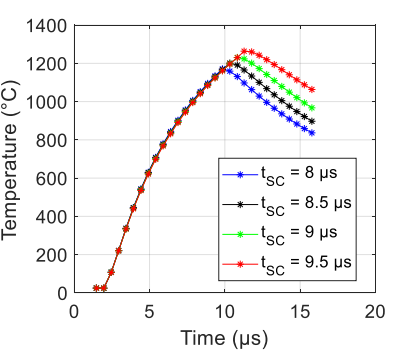

Fig. 3. (a) Estimation of critical energy for $R_{G}=47 \Omega, U_{D C}=600 \mathrm{~V}$ and $T_{C A S E}=25^{\circ} \mathrm{C}, E_{C}=0.726 \mathrm{~J}$. (b) Simulation of the corresponding junction temperature (ANSYS Multiphysics).

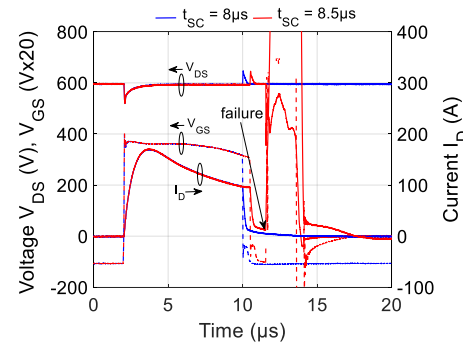

(a)

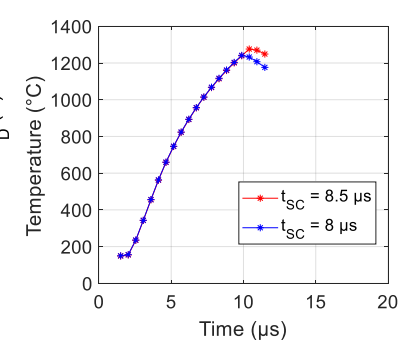

(b)
Fig. 4. (a) Estimation of critical energy for $R_{G}=47 \Omega, U_{D C}=600 \mathrm{~V}$ and $T_{C A S E}=150^{\circ} \mathrm{C}, E_{C}=0.620 \mathrm{~J}$. (b) Simulation of the corresponding junction temperature (ANSYS Multiphysics).

The same experimental protocol was also performed at $T_{C A S E}=150{ }^{\circ} \mathrm{C}$. As shown in Fig. 4.a, for $t_{S C}=8 \mu \mathrm{s}$, the DUT can safely switch off the SC current. However, a delayed failure appeared for $t_{S C}=8.5 \mu \mathrm{s}$ (about $1.5 \mu \mathrm{s}$ after the turn-off). A critical energy of about $620 \mathrm{~mJ}$ was estimated for $t_{S C}=8 \mu \mathrm{s}$.

In both cases $\left(25\right.$ and $150{ }^{\circ} \mathrm{C}$ case temperatures), the delay between the end of the SC pulse and the failure may be due to the diffusion of heat inside the DUT that delays the heating up of the most sensitive zones of the device. The lower critical energy observed for a higher $T_{C A S E}$ also points towards a thermal effect.

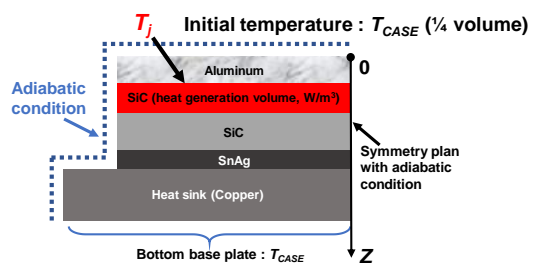

Fig. 5. Simulated power assembly structure.

In this paper, the junction temperature $\left(T_{J}\right)$ during $\mathrm{SC}$ cycles was estimated using ANSYS Multiphysics software. As shown in Fig. 5, the simplified simulation structure consists of different layers: Aluminum (4 $\mu \mathrm{m}$ thickness), 4-H $\mathrm{SiC}(180 \mu \mathrm{m}$ thickness), solder (50 $\mu \mathrm{m}$ thickness), and heat sink (Copper) layers, whose dimensions and physical parameters were individually adjusted according to the features of DUT. The 
thermal conductivity and the specific heat of 4-H SiC have also nonlinear behaviour with the temperature [24-25]. We assumed that the dissipated power is applied over a thin ( $5 \mu \mathrm{m}$ thick) $\mathrm{SiC}$ layer located just below the metallization layer, and $T_{J}$ is estimated at the interface between the metallization and the $\mathrm{SiC}$ layers (Fig. 5). The experimental power waveforms are supplied to the simulation for the calculation of $T_{J}$. Before the failure event, the simulation shows that the maximum $T_{J}$ can reach 1264 ${ }^{\circ} \mathrm{C}$ and $1276{ }^{\circ} \mathrm{C}$ in the test of $T_{C A S E}=25{ }^{\circ} \mathrm{C}$ (Fig. 3.b) and of $T_{\text {CASE }}=150{ }^{\circ} \mathrm{C}$ (Fig. 4.b), respectively. The estimated temperatures should be considered indicative only: very simplified thermal models, which do not consider the nonlinearity in all material properties nor the liquefaction of the metallization which should occur. [16, 18, 26].

\section{Aging under successive short circuit tests}

\subsection{Ageing under small-time increment of SC duration}

A much smaller time increment $\Delta t_{S C}(\sim 100 \mathrm{~ns})$ was then used to determine precisely the critical energy. In these conditions, the device experiences a very large number of SC cycles before failure. We have observed that this repetition of SC events causes the device to wear out. The corresponding experimental results are presented in this section.

The tests were conducted on DUTs for a DC voltage $U_{D C}=$ $600 \mathrm{~V}$ and a case temperature $T_{C A S E}=25^{\circ} \mathrm{C}$, with a gradual increase of the SC duration from 4.0 to $15.8 \mu$ s by steps of 100 ns. The results in Fig. 6 clearly show that the transistor can sustain SC up to $15.7 \mu \mathrm{s}$. However, several phenomena occur even before the final destruction of the DUT.

The evolutions of $V_{G S}$ (Fig. 6.a), $I_{G}$ (Fig. 6.b) and $I_{D}$ (Fig. 6.c) can be split up into four stages represented by the four colours of the waveforms. Variations are gradual within a given stage and, by contrast, discontinuous from stage to stage. This stepwise decrease seems to be related to cumulative physical degradations.

The drain current $I_{D}$ is controlled by $V_{G S}$. We notice that the repetition of SC events results in the sudden occurrence of a large transient gate leakage current $I_{G, t r}>200 \mathrm{~mA}$, for a SC duration of $7.8 \mu \mathrm{s}$ ), which then gradually increases, step by step. The increase in the gate leakage current results in the decrease of $V_{G S}$ because of the larger voltage drop across the gate resistance. This lower $V_{G S}$ then explains the step-by-step decrease of the saturation current $I_{D}$.

The energy dissipated during the first cycle $(4 \mu \mathrm{s}$ of duration) is $0.57 \mathrm{~J}$ and increases up to only $0,64 \mathrm{~J}$ in the last SC (15.8 $\mu$ s of duration) after 118 cycles. The increase in the dissipated energy with the SC duration is relatively moderate due to the gradual degradation of the DUT which causes the SC current to decrease as the tests are repeated (see Fig. 6.c).

For the tests where $t_{S C}$ ranges from $4.0 \mu \mathrm{s}$ to $7.7 \mu$ s (in blue), we can observe that the DUT does not exhibit any permanent gate leakage current $I_{G \text {,per }}$ (gate current is zero before and after the SC pulses - before $t=0 \mu \mathrm{s}$ and after $t=7.7 \mu \mathrm{s}$ in Fig. 6.b). But a transient gate leakage current is visible through the decrease in $V_{G S}$ after $4 \mu$ s (Fig. 6.a). After switch-off of the SC current, no noticeable gate leakage current can be observed in the off-state despite the negative polarization of the gate $(-5 \mathrm{~V})$. This means that the transient gate leakage current $I_{G, t r}$ is related to a reversible phenomenon such as carrier injection, and not to the breakdown of the gate oxide.

For the stage in red $\left(t_{S C}=7.8 \mu\right.$ s to $\left.11.8 \mu \mathrm{s}\right)$ we note a high transient gate leakage current $I_{G, t r}$ during the SC phase (about 0.4 A of maximum value), but we can also observe that a permanent gate leakage current $I_{G, p e r}$ exists after turn-off (about -0.1 A).
This evidence strongly supports the hypothesis of a physical degradation in the DUT, especially at the level of the gate oxide or the field oxide.

In the third and fourth stages $\left(t_{S C}=11.9 \mu\right.$ s to $14.2 \mu \mathrm{s}$, green, and $t_{S C}=14.3 \mu$ s to $15.7 \mu \mathrm{s}$, yellow), the increase in gate leakage current and the decrease in $V_{G S}$ and $I_{D}$ implies a further degradation of the gate oxide or the field oxide. Clear jumps in the gate leakage currents are visible between stages 2, 3 and 4 .

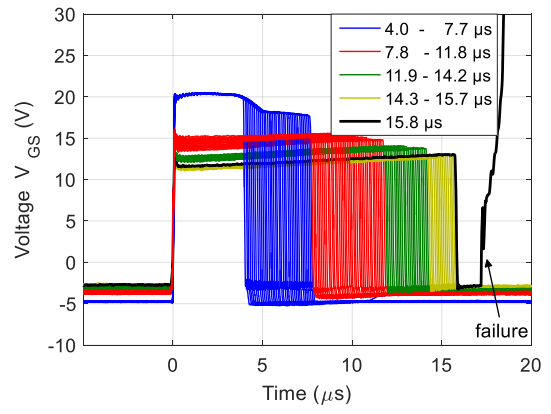

(a)

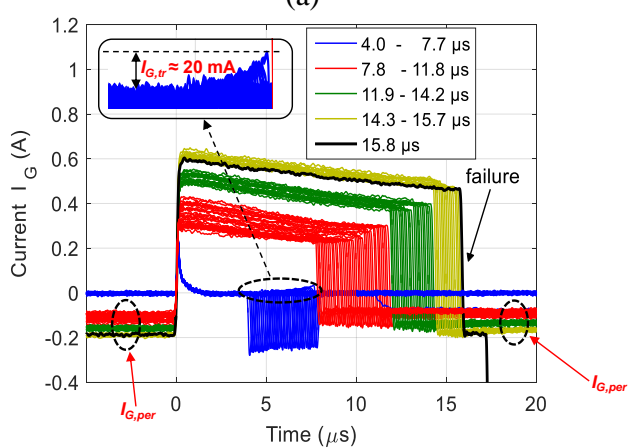

(b)

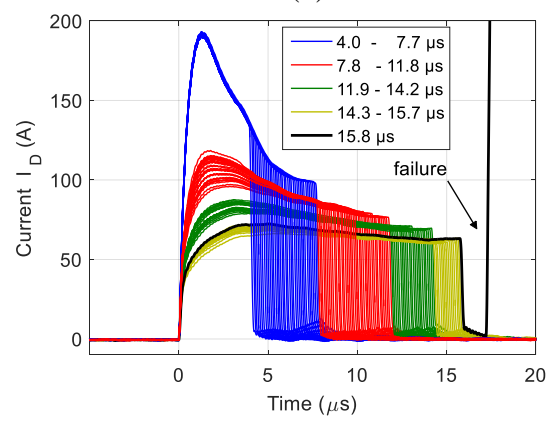

(c)

Fig. 6. Ageing under successive short circuits with 100ns increasing duration, $R_{G}=10 \Omega, T_{C A S E}=25^{\circ} \mathrm{C}, U_{D C}=600 \mathrm{~V}$.

(a) $V_{G S}$. (b) $I_{G}$. (c) $I_{D}$.

\subsection{Ageing under a fixed repetitive $S C$ duration}

To determine a safe energy dissipation (or SC duration) level for repetitive $\mathrm{SC}$, experimental ageing was performed under fixed SC duration. We considered SC energies significantly lower than $E_{C}$ estimated in the section 3 . Tests were undertaken with short SC durations $\left(t_{S C}\right)$ of $7 \mu \mathrm{s}, 4.4 \mu \mathrm{s}, 4 \mu \mathrm{s}$, and $3 \mu \mathrm{s}$.

\subsubsection{Short circuit cycle with high transient gate leakage current}

Experimental ageing results under a fixed repetitive SC duration $(7 \mu \mathrm{s})$ are presented in Fig. 7 for a dissipated energy significantly lower than the critical energy estimated in Fig. 3.a (critical energy in the same conditions is determined for a SC duration equal to $9 \mu \mathrm{s}$ ). A transient gate leakage current $I_{G, t r}$ appears at $4 \mu \mathrm{s}$ after the beginning of SC test for the $1^{\text {st }}$ cycle, and a significant $I_{G, t r}$ of about $4 \mathrm{~mA}$ is observed at the end of this cycle in the magnified $I_{G}$ graph (Fig. 7.b). Permanent leakage current $I_{G \text {,per }}$ appears at the $300^{\text {th }}$ cycle (i.e. negative permanent 
gate current before and after the SC test) and becomes more visible for the $330^{\text {th }}$ cycle. The gate leakage current causes a voltage drop in $R_{G}$ and therefore a reduction in $V_{G S}$ as depicted in Fig. 7.c. As the drain current is controlled by $V_{G S}$, it also gradually decreases during ageing, especially from the $300^{\text {th }}$ cycle to the $330^{\text {th }}$ cycle. The energy dissipated during the first cycle is $0.57 \mathrm{~J}$ and decreases down to $0.5 \mathrm{~J}$ in the last $\mathrm{SC}$ after 330 cycles due to the reduction in the SC current during ageing. The tests were stopped after 330 cycles due to the very high level of permanent gate leakage current.

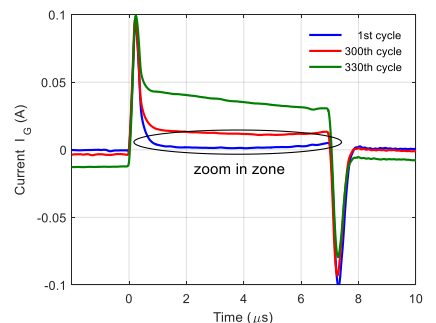

(a)

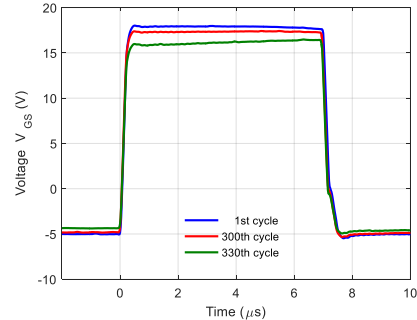

(c)

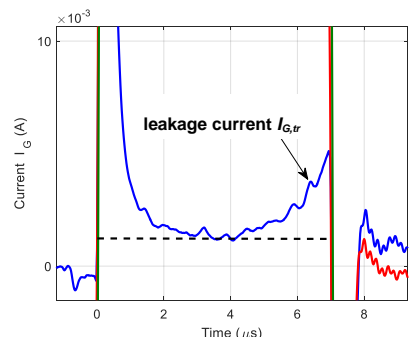

(b)

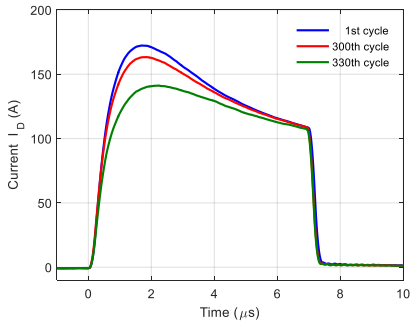

(d)
Fig. 7. (a) $I_{G}$, (b) Zoom in $I_{G}$, (c) $V_{G S}$ and (d) $I_{D}$ of DUT during repetitive short circuit, with $t_{S C}=7 \mu \mathrm{s}, R_{G}=47 \Omega, T_{C A S E}=25^{\circ} \mathrm{C}$, $U_{D C}=600 \mathrm{~V}$.

Table I - Evolution of electrical parameters of DUT under repetitive SC with $t_{S C}=7 \mu \mathrm{s}, T_{C A S E}=25^{\circ} \mathrm{C}$.

\begin{tabular}{ccccc}
\hline Cycle & $V_{T H}(\mathrm{~V})$ & $I_{G S S}$ & $\begin{array}{c}R_{D S O N} \\
(\mathrm{~m} \Omega)\end{array}$ & $\begin{array}{c}I_{D S S} \\
(\mathrm{nA})\end{array}$ \\
\hline 0 & 1.84 & $<100 \mathrm{fA}$ & 86 & 494 \\
300 & 1.08 & $>100 \mu \mathrm{A}$ & 85 & 516 \\
330 & 0.03 & $>100 \mu \mathrm{A}$ & 87 & 777 \\
\hline
\end{tabular}

The static characteristics were measured periodically during the test and the main parameters are presented in Table I. The experimental measurement conditions to obtain $V_{T H}, I_{G S S}, R_{D S O N}$ and $I_{D S S}$ are detailed in Fig. 11 of Appendix A. A substantial increase in the static gate leakage current $I_{G S S}$ from under $100 \mathrm{fA}$ in initial state to over $100 \mu \mathrm{A}$ after 300 cycles is observed. The large increase in the gate leakage current explains the significant decrease of the threshold voltage $V_{T H}$ (cf. Appendix A, Fig. 11.a) from $1.84 \mathrm{~V}$ to $1.08 \mathrm{~V}$ between the first and the $300^{\text {th }}$ cycle, before collapsing to $0.03 \mathrm{~V}$ for the $330^{\text {th }}$ cycle. This confirms the physical degradation of the gate, especially on the gate or field oxides. No change is observed on the on-state resistance, and the increase in drain leakage current is associated with the gate damage.

Because of this strong degradation of the oxide (large gate leakage current and close-to-zero threshold voltage) the DUT is not considered as functional anymore. For this particular test, with a dissipated energy sensibly lower than the critical value, we observe that a very fast degradation of the oxide appears after only 300 SC cycles.

\subsubsection{Short circuit cycle with moderate transient gate leakage current}

To determine for what energy dissipation or SC duration we can safely consider the repetition of SC cycles, ageing tests were undertaken with a SC duration $t_{S C}$ of $4 \mu \mathrm{s}$. In these conditions,
$I_{G, t r}$ is still noticed from the first cycle in Fig. 8.b, but with a much lower amplitude than for $t_{S C}=7 \mu \mathrm{s}$. It seems that $I_{G, t r}$ appears after about $3.1 \mu$ s of SC duration. The evolutions of $V_{G S}$, $I_{G}$ and $I_{D}$ are similar to what happened for $t_{S C}=7 \mu \mathrm{s}$. During the repetition of the SC cycles, an increase in gate leakage current and a decrease in $V_{G S}$ are noticeable and can be attributed to the degradation of the gate or field oxide of the DUT. We also notice once again the appearance of $I_{G \text {,per }}$ under reverse biasing of the gate after once again a low number of SC events (only 300 cycles). $I_{D}$ drops from $175 \mathrm{~A}$ at the first cycle to $150 \mathrm{~A}$ at the $378^{\text {th }}$ cycle. The decrease of the saturation current is once again explained by the reduction of the gate to source voltage $V_{G S}$. The energy dissipated during the first cycle is approximately $0.34 \mathrm{~J}$ and decreases to $0.31 \mathrm{~J}$ after 330 cycles.

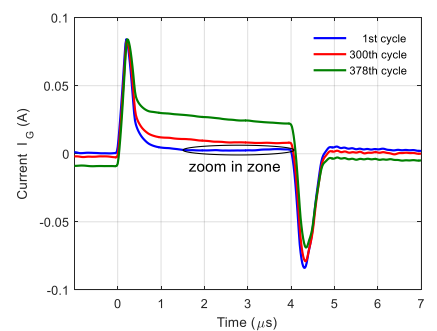

(a)

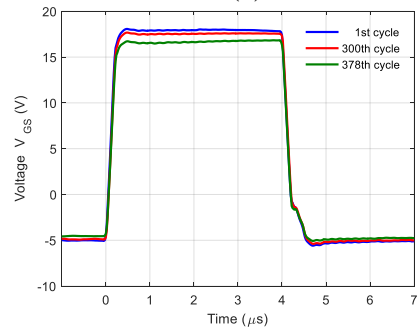

(c)

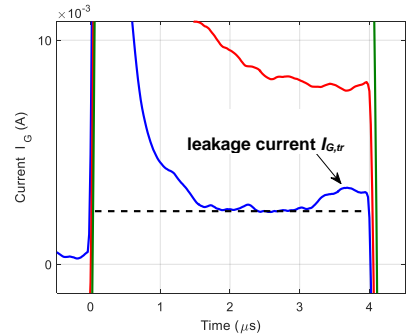

(b)

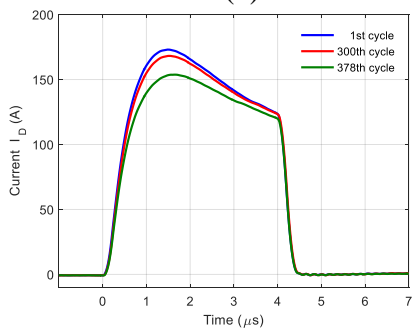

(d)
Fig. 8. (a) $I_{G}$, (b) Zoom in $I_{G}$, (c) $V_{G S}$ and (d) $I_{D}$ of DUT during repetitive short circuit, with $t_{S C}=4 \mu \mathrm{s}, R_{G}=47 \Omega, T_{C A S E}=25^{\circ} \mathrm{C}$, $U_{D C}=600 \mathrm{~V}$

Table II - Evolution of electrical parameters of DUT under repetitive SC with $t_{S C}=4 \mu \mathrm{s}, T_{C A S E}=25^{\circ} \mathrm{C}$.

\begin{tabular}{ccccc}
\hline Cycle & $V_{T H}(\mathrm{~V})$ & $I_{G S S}$ & $\begin{array}{c}R_{D S O N} \\
(\mathrm{~m} \Omega)\end{array}$ & $\begin{array}{c}I_{D S S} \\
(\mathrm{nA})\end{array}$ \\
\hline 0 & 2.02 & $<100 \mathrm{fA}$ & 68 & 9.06 \\
300 & 1.62 & $>100 \mu \mathrm{A}$ & 67 & 10.73 \\
378 & 0.05 & $>100 \mu \mathrm{A}$ & 69 & 15.53 \\
\hline
\end{tabular}

In Table II, the gate degradation is once again illustrated by the increase in $I_{G S S} . I_{G S S}$ exceeds $100 \mu \mathrm{A}$ after the $300^{\text {th }}$ cycle, which can be related to a degradation of the gate or field oxide. A reduction in the threshold voltage happens simultaneously with the increase in the gate leakage current.

Another DUT was tested and aged. The SC duration of 4.4 $\mu \mathrm{s}$ was adjusted to obtain a similar magnitude of $I_{G, t r}$ (about 2 $\mathrm{mA}$ at the end of the SC event) with that measured on the previous DUT (Fig. 8.b). The SC pulse width being different from that observed for the previous DUT shows that the features of the components are not completely identical although they have the same part reference. The static characteristics were more regularly measured on this DUT (Table III). Particularly, in the case of this DUT a great increase of $2.89 \mathrm{nA}$ in $I_{G S S}$ value has been detected after only $10 \mathrm{SC}$ cycles as shown in Table III. $I_{G S S}$ then progressively increased during the aging process from $2.89 \mathrm{nA}$ to $8.01 \mathrm{nA}$ after $100 \mathrm{SC}$ cycles. This $I_{G S S}$ increase seems to be responsible for triggering the failure process of the DUT. Finally, $I_{G S S}$ abruptly increased to about $5.4 \mathrm{~mA}$ after 150 cycles. Furthermore, using the simulation model described in section 3, the maximum $T_{J}$ was estimated to be about $840{ }^{\circ} \mathrm{C}$ during the $1^{\text {st }}$ SC cycle of this DUT. 
Table III - Evolution of electrical parameters of DUT under repetitive SC with $t_{S C}=4.4 \mu \mathrm{s}, T_{C A S E}=25^{\circ} \mathrm{C}$.

\begin{tabular}{ccccc}
\hline Cycle & $V_{T H}(\mathrm{~V})$ & $I_{G S S}$ & $\begin{array}{c}R_{D S O N} \\
(\mathrm{~m} \Omega)\end{array}$ & $\begin{array}{c}I_{D S S} \\
(\mathrm{nA})\end{array}$ \\
\hline 0 & 1.93 & $<100 \mathrm{fA}$ & 88.4 & 0.49 \\
10 & 2.01 & $2.89 \mathrm{nA}$ & 88.2 & 0.48 \\
20 & 2.07 & $4.95 \mathrm{nA}$ & 88.2 & 0.49 \\
30 & 2.09 & $5.46 \mathrm{nA}$ & 88.3 & 0.48 \\
50 & 2.11 & $6.73 \mathrm{nA}$ & 88.4 & 0.49 \\
100 & 2.14 & $8.01 \mathrm{nA}$ & 88.8 & 0.50 \\
150 & 1.08 & $5.40 \mathrm{~mA}$ & 89.5 & 0.51 \\
\hline
\end{tabular}

The evolution of $V_{G S}, I_{G}$ and $I_{D}$ waveforms was almost similar to the results observed for the previous DUT in Fig. 8. For this DUT, the energy dissipated during the first SC cycle is approximately $0.40 \mathrm{~J}$ and slightly decreases to $0.38 \mathrm{~J}$ after 150 SC cycles. In the case of the previous DUT, we did not observe any modification of $I_{G S S}$ before the failure. This can be explained by the larger interval time step which does not allow to precisely detect the evolution of the leakage current $I_{G S S}$.

The SC duration of these two DUTs ( $4 \mu \mathrm{s}$ and $4.4 \mu \mathrm{s})$ is still sufficient for a transient gate leakage current $I_{G, t r}$ to occur even during the first SC pulse. From these results, a hypothesis is that this transient gate leakage current may cause the physical degradation of the gate or field oxide. This leakage current is not necessarily an indicator of the gate degradation but it may be a precursor. As the SC stress is repeated, percolation of the defects may appear leading, to conductive paths and the continuous gate currents observed in the experiments. The influence of the gate leakage current on the repetitive robustness in SC stress is analysed in the next session by decreasing the SC duration further.

\subsubsection{Short circuit cycle without transient gate leakage current}

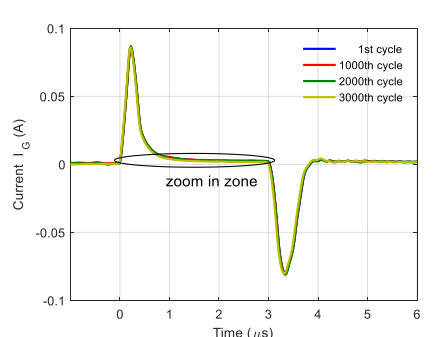

(a)

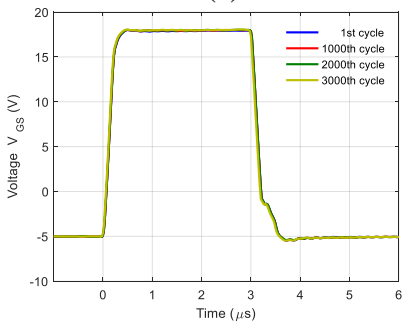

(c)

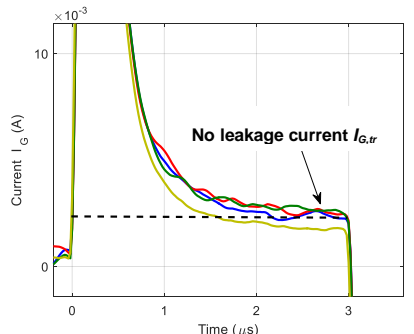

(b)

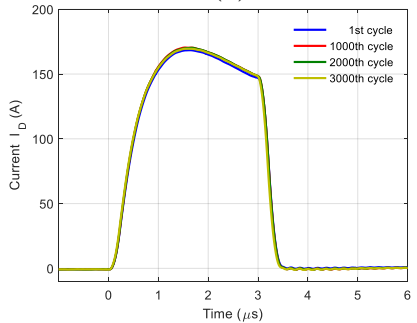

(d)
Fig. 9. (a) $I_{G}$, (b) Zoom in $I_{G}$, (c) $V_{G S}$ and (d) $I_{D}$ of DUT during repetitive short circuit, with $t_{S C}=3 \mu \mathrm{s}, R_{G}=47 \Omega, T_{C A S E}=25^{\circ} \mathrm{C}$,

$$
U_{D C}=600 \mathrm{~V} \text {. }
$$

By means of estimating instant of $I_{G, t r}$ appearance in previous DUTs, the SC duration is decreased to $3 \mu$ s to avoid $I_{G, t r}$. Fig. 9 depicts the behaviour of DUT with a SC duration of $3 \mu \mathrm{s}$ at $T_{C A S E}=25^{\circ} \mathrm{C}$. During the SC phase, we do not observe any transient gate leakage current $I_{G, t r}$ (Fig. 9.a and Fig. 9.b). The evolutions of $V_{G S}$ and $I_{D}$ are not significant during the repetition of the SC cycles. So, the DUT sustained 3000 cycles without any gate degradation or other modification of its performances. Under these conditions, if the SC pulse is short enough to avoid any transient leakage current $I_{G, t r}$ in the gate, the robustness of the DUT in repetitive SC cycles seems to be very good. As there is no evolution of the drain current during these repetitive tests, the energy dissipated remains identical at $0.26 \mathrm{~J}$ for each of the 3000 SCs.

Table IV - Evolution of electrical parameters of DUT under repetitive SC with $t_{S C}=3 \mu \mathrm{s}, T_{C A S E}=25^{\circ} \mathrm{C}$.

\begin{tabular}{ccccc}
\hline Cycle & $V_{T H}(\mathrm{~V})$ & $I_{G S S}$ & $\begin{array}{c}R_{D S O N} \\
(\mathrm{~m} \Omega)\end{array}$ & $\begin{array}{c}I_{D S S} \\
(\mathrm{nA})\end{array}$ \\
\hline 0 & 1.99 & $<100 \mathrm{fA}$ & 77 & 1.85 \\
1000 & 2.02 & $<100 \mathrm{fA}$ & 78 & 1.81 \\
2000 & 1.97 & $<100 \mathrm{fA}$ & 76 & 1.77 \\
3000 & 2.01 & $<100 \mathrm{fA}$ & 80 & 1.77 \\
\hline
\end{tabular}

The static gate leakage current remains under the level measurable with our testing setup (below $100 \mathrm{fA}$ in Table IV), and the variations of $V_{T H}, R_{D S O N}$ and $I_{D S S}$ are negligible. This reveals that there is no evolution of these electrical parameters and that the DUT operates reliably in repetitive SC cycles at this low energy level.

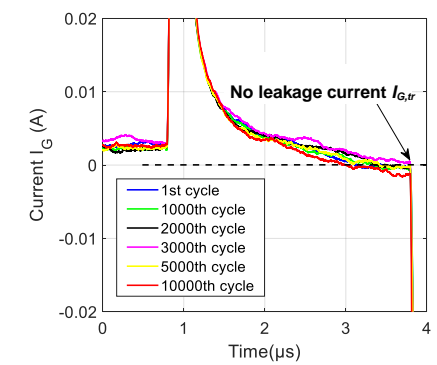

(a)

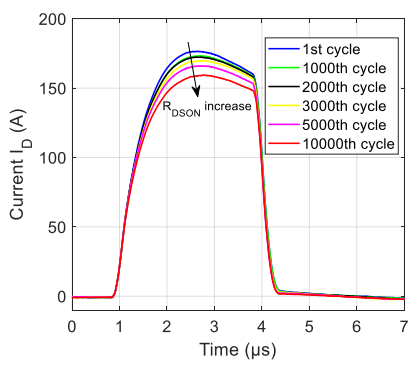

(b)
Fig. 10. (a) $I_{G}$ and (b) $I_{D}$ of DUT during repetitive short circuit, with $t_{S C}=3 \mu \mathrm{s}, R_{G}=47 \Omega, T_{C A S E}=150{ }^{\circ} \mathrm{C}, U_{D C}=600 \mathrm{~V}$.

Table V - Evolution of electrical parameters of DUT under repetitive SC with $t_{S C}=3 \mu \mathrm{s}, T_{C A S E}=150{ }^{\circ} \mathrm{C}$.

\begin{tabular}{ccccc}
\hline Cycle & $V_{T H}(\mathrm{~V})$ & $I_{G S S}$ & $\begin{array}{c}R_{D S O N} \\
(\mathrm{~m} \Omega)\end{array}$ & $\begin{array}{c}I_{D S S} \\
(\mathrm{nA})\end{array}$ \\
\hline 0 & 1.99 & $<100 \mathrm{fA}$ & 80.47 & 2.43 \\
1000 & 2.09 & $<100 \mathrm{fA}$ & 80.90 & 2.89 \\
2000 & 2.11 & $<100 \mathrm{fA}$ & 82.47 & 2.10 \\
3000 & 2.10 & $<100 \mathrm{fA}$ & 84.36 & 2.20 \\
5000 & 2.07 & $<100 \mathrm{fA}$ & 90.30 & 2.11 \\
10000 & 2.01 & $<100 \mathrm{fA}$ & 94.46 & 1.79 \\
\hline
\end{tabular}

Fig. 10 presents the same behaviour at higher case temperature $\left(150^{\circ} \mathrm{C}\right)$. Here again, with a SC duration of $3 \mu \mathrm{s}$, no significant transient gate leakage current $I_{G, t r}$ was detected during the SC phase (Fig. 10.a). Even after 10000 cycles, $I_{G S S}$, $V_{T H}$ and $I_{D S S}$ remain constant, although a significant increase of about $17 \%$ in $R_{D S O N}$ was observed (Table V). The $R_{D S O N}$ increase has been extensively studied previously on other components and can be related to the reconstruction of source metallization and/or the lifting or the degradation of bond wires. Aluminum reconstruction results in the increase of the aluminum sheet resistance and leads to depolarization of the gate to source voltage which in turns decreases the saturation drain current (Fig. 10.b) like already observed in [27]. As a consequence, the dissipated energy has clearly reduced from $0.27 \mathrm{~J}$ to $0.24 \mathrm{~J}$ between the first and the 10000th SC cycle. The simulation allows determining a maximum $T_{J}$ of about $740{ }^{\circ} \mathrm{C}$ for the $1^{\text {st }} \mathrm{SC}$ cycle. It is interesting to note that this is lower than the temperature estimated in section $4.2 .2\left(T_{J, \max }=840{ }^{\circ} \mathrm{C}\right)$. The transient gate leakage current $I_{G, t r}$ would therefore possibly appear, once the junction temperature reaches a critical value of approximately $840{ }^{\circ} \mathrm{C}$, difficult to estimate precisely seeing as the uncertainties linked to the thermal simulation (physical parameters and device geometry). 


\section{Conclusion}

For silicon IGBTs or MOSFETs, it is possible to define a single critical energy. Below this threshold, the devices can sustain many SC events. On the contrary, they fail as soon as any $\mathrm{SC}$ event exceeds the critical energy level. In the case of $\mathrm{SiC}$ MOSFETs, the separation between safe operating operations in $\mathrm{SC}$ and failure is not so clear, and must be carefully analysed, especially if the device must support several SC events over its lifetime. For all these reasons, we introduce another parameter, the "repetitive critical energy". This parameter corresponds to the highest SC energy that a device is able to sustain repetitively. Above the repetitive critical energy threshold, the DUT degrades rapidly during repetitive SC. Below this threshold, the DUT can sustain a large number of SC cycles.

From our observations, it appears that the repetitive critical energy value is dictated by the occurrence of a transient gate leakage current during the SC pulse, which we suppose gradually degrades the gate oxide or the field oxide. This wearout mechanism eventually results in the large gate current observed after a few hundreds of SC pulses. This means that the apparition of a transient gate leakage current can indicate a premature ageing of the component and can be used to predict a future failure of the component.

\section{Acknowledgment}

This work was funded as part of the French GENOMEPREMICES PIA initiative

\section{APPENDIX A}

Measurement of electric parameters as ageing indicators using B1505 Agilent curve tracer.

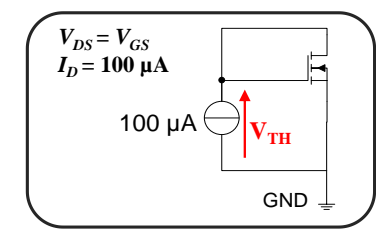

(a)

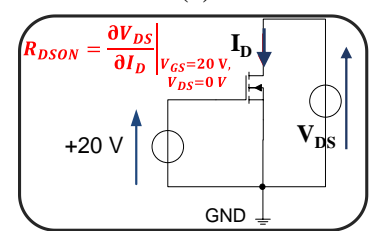

(c)

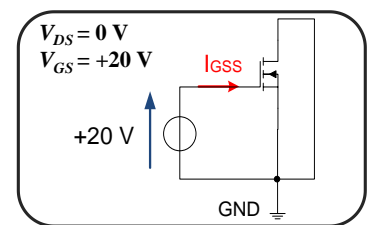

(b)

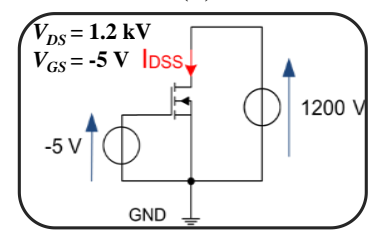

(d)
Fig. 11. Circuit diagram for measurement of (a) threshold voltage $V_{T H}$, (b) Gate leakage current $I_{G S S}$, (c) on-state resistance $R_{D S O N}$ and (d) Drain leakage current IDSS.

\section{References}

[1] J. Millán, et al., A survey of wide bandgap power semiconductor devices, IEEE Trans. Power Electron., 29 (5) (May 2014), pp. 2155-2163.

[2] J. Sun, et al., Comparison and analysis of short circuit capability of $1200 \mathrm{~V}$ single-chip SiC MOSFET and Si IGBT, IEEE-13th Int. Forum Wide Bandgap Semiconductor China (SSLChina: IFWS), Beijing, China, 15-17 Nov. 2016.

[3] C. Ionita, et al., On the short-circuit and avalanche ruggedness reliability assessment of SiC MOSFET modules, Microelectron. Reliab., 71 (Apr. 2017), pp. 6-16.

[4] A. Castellazi, et al., Transient out-of-SOA robustness of $\mathrm{SiC}$ power MOSFET, IEEE-Int. Reliab. Phys. Symp. (IRPS), Monterey, CA, USA, 2-6 Apr. 2017.

[5] A. März, et al., Explaining the short-circuit capability of $\mathrm{SiC}$ MOSFETs by using a simple thermal transmission-line model, 18th Eur. Conf. Power Electron. Appl. (EPE ECCE Eur.), Karlsruhe, Germany, 5-9 Sep. 2016.

[6] X. Zhou, et al., Investigations on the degradation of $1.2-\mathrm{kV} 4 \mathrm{H}-$ SiC MOSFETs under repetitive short-circuit tests, IEEE Trans. Electron Devices, 63 (11) (Nov. 2016), pp. 4346-4351.

[7] P. Diaz Reigosa, et al., Investigation on the short circuit safe operation area of SiC MOSFET power modules, IEEE-Energy Convers. Congr. Expo., Milwaukee, WI, USA, 18-22 Sep. 2016.

[8] G. Romano, et al., Short-circuit failure mechanism of SiC power MOSFETs, IEEE-27th Int. Symp. Power Semicond. Devices Ics (ISPSD), Hong Kong, China, May 2015.

[9] C. Chen, et al., Study of short-circuit robustness of $\mathrm{SiC}$ MOSFETs, analysis of the failure modes and comparison with BJTs, Microelectron. Reliab., 55 (9-10) (Aug.-Sep. 2015), pp. 1708-1713.

[10] H. Du, et al., Implications of short-circuit events on power cycling of $1.2-\mathrm{kV} / 20-\mathrm{A}$ SiC MOSFET power modules, Microelectron. Reliab., 100-101 (Sep. 2019), pp. 1-6.

[11] T. T. Nguyen, et al., Gate oxide reliability issues of $\mathrm{SiC}$ MOSFETs under short-circuit operation, IEEE Trans. Power Electron., 30 (5) (May 2015), pp. 2445-2455.

[12] F. Boige, et al., Gate leakage-current analysis and modelling of planar and trench power SiC MOSFET devices in extreme shortcircuit operation, Microelectron. Reliab., 76-77 (Sep. 2017), pp. $532-538$.

[13] J. An, et al., Experimental and theoretical analyses of gate oxide and junction reliability for $4 \mathrm{H}-\mathrm{SiC}$ MOSFET under short-circuit operation, JPN. J. Appl. Phys., 55 (12) (Nov. 2016).

[14] A. K. Agarwal, et al., Temperature dependence of FowlerNordheim current in $6 \mathrm{H}-$ and $4 \mathrm{H}-\mathrm{SiC}$ MOS capacitors, IEEE Electron Device Lett., 18 (12) (Dec. 1997), pp. 592-594.

[15] F. Boige, et al., Physical origin of the gate current surge during short-circuit operation of SiC MOSFET, IEEE Electron Device Lett., 40 (5) (May 2019), pp. 666-669.

[16] T. H. Duong, et al., Electro-thermal simulation of $1200 \mathrm{~V} \mathrm{4H-}$ SiC MOSFET short-circuit SOA, IEEE-27th Int. Symp. Power Semicond. Devices Ics (ISPSD), Hong Kong, China, May 2015.

[17] C. Raynaud, et al., Comparison of high voltage and high temperature performances of wide bandgap semiconductors for vertical power devices, Diamond Relat. Mater., 19 (1) (Jan. 2010), pp. 1-6.

[18] F. Boige, et al., Ensure an original and safe "fail-to-open" mode in planar and trench power SiC MOSFET devices in extreme short-circuit operation, Microelectron. Reliab., 88-90 (Sep. 2018), pp. 598-603.

[19] S. Mbarek, et al., Short-circuit robustness test and in depth microstructural analysis study of SiC MOSFET, Microelectron. Reliab., 76-77 (Sep. 2017), pp. 527-531.

[20] P.D. Reigosa, et al., Failure analysis of a degraded $1.2 \mathrm{kV} \mathrm{SiC}$ MOSFET after short circuit at high temperature, IEEE Int. Symp. Phys. Failure Anal. Integr. Circuits (IPFA), Singapore, Jul. 2018.

[21] M. Otsuki, et al., A study on the short-circuit capability of fieldstop IGBTs, IEEE Trans. Electron Devices, 50 (6) (Jun. 2003), pp. 1525-1531.

[22] J. Yamashita, et al., A study on the IGBT's turn-off failure and inhomogeneous operation, IEEE-6th Int. Symp. Power Semicond. Devices Ics (ISPSD), Davos, Switzerland, May-Jun. 1994.

[23] S. Lefebvre, et al., Experimental behavior of single chip IGBT and COOLMOSTM devices under repetitive short-circuit conditions, IEEE Trans. Electron Devices, 52 (2) (Feb. 2005), pp. 276-283.

[24] L. Hitova, et al., Heat capacity of $4 \mathrm{H}-\mathrm{SiC}$ determined by differential scanning calorimetry, J. Electrochem. Soc., 147 (9) (Feb. 2000), pp. 3546-3547.

[25] R. Wei, et al., Thermal conductivity of $4 \mathrm{H}-\mathrm{SiC}$ single crystals, J. Appl. Phys., 113 (5) (Feb. 2000), 053503.

[26] D-P. Sadik, et al., Short-circuit protection circuits for siliconcarbide power transistors, IEEE Trans. Ind. Electron., 63 (4) (Apr. 2016), pp. 1995-2004.

[27] M. Berkani, et al., Saturation current and on-resistance correlation during repetitive short circuit conditions on $\mathrm{SiC}$ JFETs transistors, IEEE Trans. Power Electron., 28 (2) (Feb. 2013), pp. 621-624. 